\title{
A STUDY OF AEROBIC BACTERIOLOGICAL PROFILE ALONG WITH ANTIBIOTIC SUSCEPTIBILITY PATTERN IN CHRONIC SUPPURATIVE OTITIS MEDIA
}

\section{Microbiology}

\section{Dr. Dinesh Gadekar}

Medical Officer, Pimpri Chinchwad Municipal Corporation's Postgraduate Institute, Yashwantrao Chavan Memorial Hospital, Pimpri, Pune-18

Professor, Department of Microbiology, JIIU'S Indian Institute of Medical Science and Research, Warudi, District Jalna, Maharashtra, India. *Corresponding Author

Dr Atul Desale

Assistant Professor, Department Of PSM,Dr D. Y. Patil Medical College, Pimpri, Pune- 18

\section{Dr. Tushar Baheti}

Assistant Professor, Department of Pharmacology, Rural Medical College, Loni bk, District Ahmednagar

\section{ABSTRACT}

Introduction: Chronic suppurative otitis media (CSOM) is a destructive and persistent disease with irreversible sequel and can proceed to serious intra and / or extra cranial complications. Causative agents of infection include bacteria, fungi and viruses with bacteria being the commonest cause. Hence bacteriological studies of CSOM are important for determining effective antibiotic choice and surveillance of bacterial patterns and their relative sensitivities.

Materials and Methods: Total 157 patients having CSOM were included in the study. Ear discharge was processed with standard Microbiological procedures.

Results: On aerobic culture Staphylococcus aureus 58 (36.96\%) was the most common isolate followed by Pseudomonas aeruginosa 35 (21.21\%). Fungal culture yielded $19(11.2 \%)$ isolates.

Conclusion: Evaluation of microbiological pattern and antibiotic sensitivity of isolates is necessary to decrease the potential risk of complications of CSOM by early institution of appropriate treatment.

\section{KEYWORDS}

Chronic Suppurative Otitis Media, Aerobic bacteriological profile, Antibiotic susceptibility test

\section{INTRODUCTION}

Otitis media is common childhood illness second in frequency only to viral upper respiratory tract infection. Chronic suppurative otitis media (CSOM) is a result of an initial episode of acute otitis media (AOM) and is characterised by a persistent discharge from the middle ear through a tympanic perforation. It is an important cause of hearing loss particularly in developing world. ${ }^{3}$ CSOM is a destructive and persistent disease with irreversible sequel and can proceed to serious intra as well as extra cranial complications. ${ }^{4}$ Causative agents of infection include bacteria, fungi and viruses with bacteria being the commonest cause

The microbiological flora of middle ear in chronic otitis media includes organisms like Staphylococcus aureus, Pseudomonas aeruginosa, Escherichia coli, Klebsiella pneumoniae and anaerobic bacteria.

Treatment of CSOM should be guided by culture and suggest choices for instituting narrowest spectrum systemic antibiotics assuring a most effective and cost-effective protocol of treatment. ${ }^{7}$ Indiscriminate, haphazard and half-hearted use of antibiotics and poor follow up of patients has resulted in persistence of low grade infections. In-vitro antibiotic susceptibility pattern is very important for the clinicians to plan the general outline of treatment for a patient with CSOM.

Hence bacteriological studies of CSOM are important for determining effective antibiotic choice and surveillance of bacterial patterns along with their relative sensitivities

The present study was undertaken to provide baseline data on aerobic bacteriological profile of CSOM in our area as this is the first of its kind study from this institute. The study would also provide information regarding antimicrobial susceptibility of the isolates to commonly used antibiotics in this institute.

\section{MATERIALS AND METHODS}

The study was conducted in Microbiology Department, at a tertiary care centre during January 2012 to June 2013. A total 157 patients of CSOM (including 12 bilateral cases; hence a total of 169 ear swabs) were examined. Clearance of the institutional ethical committee was obtained before initiation of the study. It was a prospective cross sectional study.

Patients of all age groups and both sexes attending outpatient department (OPD) and those admitted in our tertiary care centre and clinically diagnosed as suffering from CSOM by ENT Surgeon were included in the study. Patients who have taken topical or systemic antibiotics in last 7 days were excluded from the study.

\section{Sample collection ${ }^{9}$}

Written consent of patient / parent of a minor patient was taken before collection of sample.

Patient's detailed history consisting of present complaints, treatment history, and history of investigations was taken.

The external auditory canal of discharging ear was cleaned with sterile cotton. Under all aseptic precautions discharge was collected with two cotton swabs with help of sterile ear speculum, taking care not to touch external ear canal. Swabs were transported in sterile containers to the microbiology laboratory; each specimen was labelled with patient's name, age, sex, registration number, laterality of ear.

\section{Laboratory procedure}

Gross appearance of the discharge including colour, odour and consistency were noted.

\section{Microscopy $^{10,1}$}

Primary smear was made from one of the swabs. Gram staining was done and observed under microscope and presence of organisms, pus cells were noted. Potassium hydroxide $(\mathrm{KOH})$ mount was done from the same swab and observed under microscope.

\section{Culture ${ }^{9,10,12,13}$}

Second swab was cultured on Blood Agar (BA), MacConkey agar (MA) and incubated aerobically at $370 \mathrm{C}$ for 24 hours. The same swab was also inoculated on two Sabouraud's dextrose agar (SDA) one was incubated at $37^{\circ} \mathrm{Celsius}$ and other was kept at room temperature as per standard microbiological procedures.

Blood and MacConkey agar plates were observed for growth of microorganisms. If no growth was present plates were further incubated for next 24 hours, if still there was no growth then it was reported as sterile and plates were discarded. SDA slants were observed thrice weekly for four weeks before reporting sterile.

In case of growth colony / colonies were identified by colony characteristics, morphology, motility and biochemical reactions as per 
standard guidelines.

\section{Antibiotic susceptibility test}

It was done for all bacterial isolates by Kirby-Bauer disc diffusion method as per Clinical Laboratory Standards Institute (CLSI) guidelines. Following antibiotic discs procured commercially from Hi-media Laboratories ltd. were used.

Antibiotic(Symbol-Concentration in $\mathrm{mcg}$ ): Erythromycin(E-15), Clindamycin(C-2), Cefoxitin(CX-30), Ampicillin(AMP-10), Cotrimoxazole(COT-1.25/23.75), Linezolid(LZ-15), Tetracycline(TE$30)$, Vancomycin ( VA - 30), Ciproflox a c in ( C I P - 5), Gentamycin(GEN10), Ceftazidine(CAZ-30), Piperacillin(PI-100), Amikacin(AK-30), Aztreonam(AT-30), Cefepime(CPM-30), Imipenem(IPM-10), Piperacillin-tazobactam(PIT-100/10), Cefotaxime(CTX-30), Ceftazidim(CAZ-30).

Growth of Staphylococcus aureus on Blood agar and Antibiotic susceptibility test on Mueller-Hinton agar showing MRSA
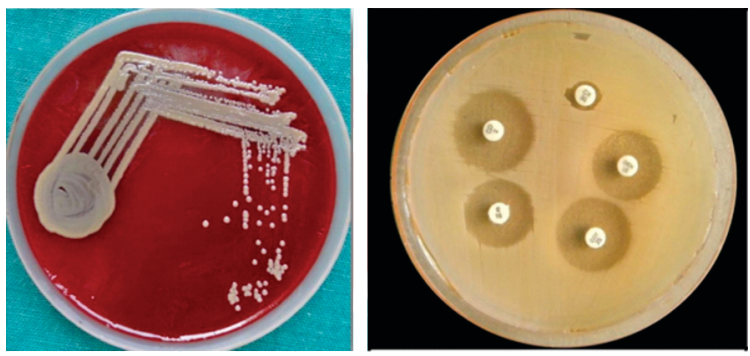

\section{RESULTS}

A total of 157 patients having Chronic Suppurative Otitis Media were included. There were 12 patients having bilateral infection. Hence total 169 swabs (145 unilateral cases giving 145 swabs and 12 bilateral cases giving 24 swabs) were examined of which 14 swabs did not yield any growth. On aerobic bacteriological culture they yielded 165 bacterial isolates. While on fungal culture they yielded total 19 isolates.

Table No. 1: Age and Gender wise distribution

\begin{tabular}{|c|c|c|c|c|c|c|}
\hline Age & \multicolumn{2}{|c|}{ Male } & \multicolumn{2}{c|}{ Female } & \multicolumn{2}{c|}{ Total } \\
\hline Group(Years) & & & & & & \\
\hline & Number & $\mathbf{\%}$ & Number & $\mathbf{\%}$ & Number & $\%$ \\
\hline$<10$ & 33 & 38.37 & 28 & 39.43 & 61 & $\mathbf{3 8 . 8 5}$ \\
\hline $11-20$ & 18 & 20.93 & 14 & 19.71 & 32 & 20.38 \\
\hline $21-30$ & 14 & 16.27 & 12 & 16.90 & 26 & 16.56 \\
\hline $31-40$ & 12 & 13.95 & 10 & 14.08 & 22 & 14.01 \\
\hline$>40$ & 9 & 10.46 & 7 & 09.85 & 16 & 10.19 \\
\hline Total & $\mathbf{8 6}$ & 100 & $\mathbf{7 1}$ & 100 & $\mathbf{1 5 7}$ & 100 \\
\hline
\end{tabular}

Chi Square Test $=0.063, \mathrm{p}>0.05$ hence Not Significant

Out of 157 patients $86(54.77 \%)$ were male and $71(45.22 \%)$ were female showing slight male predominance. Above results also show that maximum number of cases of CSOM were below age of 10 years comprising of $38.85 \%$ of total cases.

Out of 157 cases, there were $116(73.88 \%)$ of cases were from rural area while 41 (26.11) cases were from urban area, suggesting higher prevalence of CSOM in rural area which was statistically significant.

Table No. 2: Aerobic bacteriological organisms Isolated

\begin{tabular}{|c|c|c|c|c|}
\hline \multicolumn{2}{|c|}{ Organism } & \multirow{2}{*}{$\begin{array}{l}\text { Number of } \\
\text { Isolates }\end{array}$} & \multicolumn{2}{|c|}{ Percentage } \\
\hline \multirow{5}{*}{$\begin{array}{l}\text { Gram } \\
\text { Positive }\end{array}$} & Staphylococcus aureus & & 35.15 & \multirow[t]{5}{*}{40.60} \\
\hline & \multirow{2}{*}{$\begin{array}{l}\text { Coagulase negative } \\
\text { staphylococci }\end{array}$} & \multirow[t]{2}{*}{9} & 5.45 & \\
\hline & & & 21.21 & \\
\hline & Pseudomonas aeruginosa & 35 & 13.94 & \\
\hline & Proteus mirabilis & 23 & 5.45 & \\
\hline \multirow{6}{*}{$\begin{array}{l}\text { Gram } \\
\text { Negative }\end{array}$} & Proteus vulgaris & 9 & 10.30 & \multirow[t]{5}{*}{59.39} \\
\hline & Klebsiella pneumoniae & 17 & 4.24 & \\
\hline & Escherichia coli & 7 & 3.03 & \\
\hline & Citrobacter freundii & 5 & 1.21 & \\
\hline & Acinetobacter baumannii & 2 & 100 & \\
\hline & Total & 165 & 100 & 100 \\
\hline
\end{tabular}

$74 \quad H$ International Journal of Scientific Research
Out of 165 islets, $67(40.60 \%)$ were Gram positive while $98(59.39 \%)$ were Gram negative. Above table shows Staphylococcus aureus 58 $(36.96 \%)$ as most common isolate followed by Pseudomonas aeruginosa $35(21.21 \%)$

Table No. 3: Outcome of fungal culture

\begin{tabular}{|l|c|c|}
\hline \multicolumn{1}{|c|}{ Isolates } & Number & Percentage \\
\hline Candida albicans & 11 & 57.89 \\
\hline Aspergilluas niger & 5 & 26.32 \\
\hline Aspergillus flavus & 3 & 15.79 \\
\hline Total & 19 & 100 \\
\hline
\end{tabular}

Out of total 19 swabs showing fungal growth, there were 11 isolates of Candida albicans, five isolates of Aspergillus niger and three isolates of Aspergillus flavus.

Table No. 4: Susceptibility of Staphylococcus aureus

\begin{tabular}{|c|c|c|c|c|c|c|c|c|c|c|}
\hline \multirow{2}{*}{$\begin{array}{c}\text { Organi } \\
\text { sm }\end{array}$} & \multicolumn{7}{|c|}{ Antibiotic- number and percentage of susceptible } \\
isolates \\
\cline { 2 - 11 } & E & CD & CX & AMP & COT & LZ & TE & VA & CIP & GEN \\
\hline (no) & $\mathbf{( \% )}$ & $\mathbf{( \% )}$ & $\mathbf{( \% )}$ & $\mathbf{( \% )}$ & $\mathbf{( \% )}$ & $\mathbf{( \% )}$ & $\mathbf{( \% )}$ & $\mathbf{( \% )}$ & $\mathbf{( \% )}$ & $\mathbf{( \% )}$ \\
\hline MSSA & 36 & 44 & 51 & 16 & 30 & 51 & 24 & 51 & 32 & 39 \\
\hline $\mathbf{( 5 1 )}$ & $\begin{array}{c}(70.5 \\
9)\end{array}$ & $(86.2$ & $(100)$ & $(31.37)$ & $(58.82)$ & $(100)$ & $(47.06)$ & $(100)$ & $(62.7$ & $(76.47)$ \\
\hline MRSA & 2 & 5 & 0 & 0 & 3 & 7 & 3 & 7 & 4 & 5 \\
\hline $\mathbf{( 7 )}$ & $(28.5$ & $(71.4$ & $(0)$ & $(0)$ & $(42.85)$ & $(100)$ & $(42.85)$ & $(100)$ & $(57.1$ & $(71.43)$ \\
\hline MSCO & 4 & 7 & 8 & 2 & 4 & 8 & 2 & 8 & 3 & 6 \\
NS & & & & & & & & & & \\
\hline (8) & $(50)$ & $(87.5)$ & $(100)$ & $(25)$ & $(50)$ & $(100)$ & $(25)$ & $(100)$ & $(37)$ & $(75)$ \\
\hline $\begin{array}{c}\text { MRCO } \\
\text { NS(1) }\end{array}$ & $1(10)$ & $1(10$ & $0(0)$ & $0(0)$ & $0(0)$ & $1(10$ & $0(0)$ & $1(10$ & $1(10$ & $(100)$ \\
\hline
\end{tabular}

Table No.4 shows that out of 58 isolates of Staphylococcus spp. 51 were methicillin sensitive Staphylococcus aureus (MSSA) while seven were methicillin resistance Staphylococcus aureus (MRSA). Out of nine isolates of Coagulase negative staphylococci (CONS), eight were methicillin sensitive CONS while there was one isolate of methicillin resistant CONS.

All of them sowed $100 \%$ susceptibility to vancomycin and linezolid while least susceptibility was noted to tetracycline and ampicillin.

Table No. 5: Antibiotic susceptibility of Pseudomonas aeruginosa

\begin{tabular}{|l|c|c|}
\hline \multirow{2}{*}{ Antibiotic } & \multicolumn{2}{|c|}{ Susceptibility } \\
\cline { 2 - 3 } & Number & Percentage \\
\hline CIP & 24 & 68.57 \\
\hline GEN & 26 & 74.28 \\
\hline CAZ & 29 & 82.86 \\
\hline PI & 27 & 77.14 \\
\hline AK & 28 & 80 \\
\hline AT & 24 & 68.57 \\
\hline CPM & 29 & 82.86 \\
\hline IPM & 31 & 88.57 \\
\hline PIT & 30 & 85.71 \\
\hline
\end{tabular}

It showed highest susceptibility to imipenem followed by piperacillintazobactam, ceftazidime and cefepime. It was least susceptible to ciprofloxacin.

Table No.6: Antibiotic susceptibility of Enterobacteriaceae spp.

\begin{tabular}{|c|c|c|c|c|c|c|c|c|c|c|c|}
\hline \multirow{2}{*}{$\begin{array}{c}\text { Organism } \\
(\text { no) }\end{array}$} & \multicolumn{6}{|c|}{ Antibiotic- number and percentage of susceptible isolates } \\
\cline { 2 - 14 } & AMP & COT & CIP & GEN & PI & AK & AT & IPM & PIT & CTX & TE \\
\cline { 2 - 13 } & $(\%)$ & $(\%)$ & $(\%)$ & $(\%)$ & $(\%)$ & $(\%)$ & $(\%)$ & $(\%)$ & $(\%)$ & $(\%)$ & $(\%)$ \\
\hline $\begin{array}{c}\text { Proteus } \\
\text { Mirabilis } \\
(\mathbf{2 3 )}\end{array}$ & 5 & 11 & 18 & 15 & 17 & 18 & 15 & 20 & 19 & 17 & 10 \\
\cline { 2 - 14 } & $(22)$ & $(48)$ & $(78)$ & $(65)$ & $(74)$ & $(78)$ & $(65)$ & & $(83)$ & $(74)$ & $(43)$ \\
\hline $\begin{array}{c}\text { Proteus } \\
\text { Vulgaris } \\
(9)\end{array}$ & 2 & 4 & 7 & 6 & 8 & 7 & 6 & 7 & 8 & 7 & 3 \\
\cline { 2 - 13 } & $(22)$ & $(44)$ & $(78)$ & $(67)$ & $(89)$ & $(78)$ & $(67)$ & $(78)$ & $(89)$ & $(78)$ & $(33)$ \\
\hline $\begin{array}{c}\text { Klebsiella } \\
\text { pneumoniae } \\
(17)\end{array}$ & 4 & 9 & 12 & 12 & 13 & 14 & 12 & 15 & 14 & 11 & 10 \\
\cline { 2 - 12 } & $(24)$ & $(73)$ & $(71)$ & $(76)$ & $(82)$ & $(71)$ & $(88)$ & $(82)$ & $(65)$ & $(59)$ \\
\hline $\begin{array}{c}\text { E coli } \\
(7)\end{array}$ & 2 & 4 & 5 & 5 & 5 & 6 & 4 & 6 & 6 & 4 & 3 \\
\cline { 2 - 11 } & $(29)$ & $(57)$ & $(71)$ & $(71)$ & $(71)$ & $(86)$ & $(57)$ & $(86)$ & $(86)$ & $(57)$ & $(43)$ \\
\hline
\end{tabular}




\begin{tabular}{|c|c|c|c|c|c|c|c|c|c|c|c|}
\hline $\begin{array}{c}\text { Citrobacter } \\
\text { freundii } \\
(\mathbf{5})\end{array}$ & 1 & 2 & 3 & 3 & 4 & 4 & 3 & 4 & 4 & 2 & 2 \\
\cline { 2 - 11 } & $(20)$ & $(40)$ & $60)$ & $60)$ & $(80)$ & $(80)$ & $(60)$ & $(80)$ & $(80)$ & $(40)$ & $(40)$ \\
\hline
\end{tabular}

Table No.6 shows antibiotic susceptibility of Enterobacteriaceae species in which maximum sensitivity was seen to imipenam, piperacillin- tazobactam, amikacin while least sensitivity was seen to co-trimoxazole and ampicillin.

\section{DISCUSSION}

Present study was undertaken to evaluate aerobic bacteriological and fungal profile in chronic suppurative otitis media (CSOM) and to study their antimicrobial susceptibility.

In our study, higher prevalence of CSOM in males than females can be an incidental finding and there is no gender predilection as mentioned by Ayson et al. ${ }^{7}$ and Shyamala and Reddy ${ }^{15}$.

Most common age group affected in present study was between $0-10$ years, comprising $61(38.85 \%)$ of total patients followed by $11-20$ years $(20.38 \%)$. Thus a total of $59.23 \%$ of cases were below 20 years. This is consistent with Poorey and $\operatorname{Iyer}^{4}(0-10 \mathrm{yrs})$, Agrawal et al ${ }^{16}(0-$ $20 \mathrm{yrs})$, Shyamala and Reddy ${ }^{15}(0-20 \mathrm{yrs})$, Prakash et al (0-20yrs) and Shazia and $\mathrm{RaO}^{17}(5-20 \mathrm{yrs})$

In present study, $73.88 \%$ of the patients are from rural area, as compared to $26.11 \%$ from urban area. The difference is statistically significant as most of the patients coming to our institute are from rural area. Other authors who had predominant rural population in their study were Agrawal et al ${ }^{16}$ and Kumar and Seth ${ }^{18}$.

In present study, Gram negative organisms $(59.4 \%)$ outnumbered Gram positive $(40.6 \%)$ organisms. This is in agreement with Malkappa et $a l^{19}$ Motayo et $a l^{5}$ and Wariso and Ibe et al. ${ }^{20}$

In present study, the most common organism isolated was Staphylococcus aureus, which were 58 in number constituting $35.15 \%$ of the total isolates. These findings are consistent with Agrawal et $\mathrm{al}^{16,}$ Kumar and $\operatorname{Seth}^{18}$, Shyamalla and Reddy ${ }^{15}$ Nikakhlagh et $\mathrm{al}^{6}$, Loy et al ${ }^{21}$

We isolated nine Coagulase negative staphylococci (CONS) which was $5.45 \%$ of total isolates.Agrawal et al $^{16}(6.08 \%)$, Shazia and Rao ${ }^{17}(6.7 \%)$ were having similar findings.

In present study Pseudomonas aeruginosa was found as the second most common isolates with total number of isolates being $35(21.21 \%$ of total isolates). Our findings are consistent with Singh et al $l^{22}(24 \%)$ and Prakash et $^{3} l^{3}(19.89 \%)$.

In our study we recovered 32 isolates of Proteus spp. out of which 23 were that of Proteus mirabilis while nine were Proteus vulgaris. Proteus spp. accounted for $19.30 \%$ of total isolates. Our findings are consistent with Kusuma et al ${ }^{23}(16.1 \%)$, Ashish et al $^{24}(20.6 \%)$

We recovered 17 isolates of Klebsiella pneumoniae species, $10.30 \%$ of the total isolates. Similar findings were recorded by Singh et al ${ }^{22}(8 \%)$, Kumar and $\operatorname{Seth}^{18}(9.1 \%)$, and Prakash etal $^{3}(9.42 \%)$.

On mycological study of ear discharge we found a total of 19 samples that yielded fungal growth; $11.24 \%$ of total number of samples, constituting 11 isolates of Candida albicans, five isolates of Aspergillus niger, three isolates of Aspergillus flavus. Our findings are consistent with Vishwanath et $a l^{26}(9.6 \%)$ and Prakash et al $l^{3}(12.25 \%)$.

\section{Antibiotic susceptibility pattern of bacterial isolets}

Staphylococcus aureus: In present study, there were 51 isolates of Methicillin sensitive Staphylococcus aureus (MSSA) and 7 isolates of Methicillin Resistant Staphylococcus aureus (MRSA)

\section{Antibiotic susceptibility pattern of MSSA}

In present study, $100 \%$ sensitivity was found to linezolid, vancomycin. This is in consistence with various studies. ${ }^{8,16}$ while Kumar and Sheth ${ }^{18}$ less sensitivity

In present study, $86.27 \%$ of the isolates were sensitive to clindamycin. These findings are consistent with some studies ${ }^{22,26}$

Least sensitivity was found to ampicillin this is in consistence with some studies ${ }^{7,16}$

\section{Antibiotic susceptibility pattern of MRSA}

In present study, seven isolates of MRSA were recovered. They showed $100 \%$ sensitivity to linezolid and vancomycin and their sensitivity to clindamycin and gentamycin was $71.42 \%$ each followed by co-trimoxazole and tetracycline $42.85 \%$ each. It showed lower sensitivity to erythromycin $(28.57 \%)$. All the strains were resistant to ampicillin and cefoxitin. These findings are consistent with findings of Bansal et al $^{27}$

In present study good sensitivity is shown to non beta-lactam antibiotics this may be due to most of our patients are those attending outpatient department and possibly having community acquired infection.

\section{Antibiotic susceptibility pattern of CONS}

In present study, there were 9 isolates of CONS were isolated including 1 isolate of MRCONS. All isolates were sensitivity to vancomycin and linezolid while least sensitivity was shown to tetracycline and ampicillin. These findings are consistent with findings of some studies $^{22,19,26,21}$

\section{Antibiotic susceptibility pattern of Pseudomonas aeruginosa}

In present study, Pseudomonas aeruginosa 35 (21.21\%) was found to be the second most common isolate. It showed highest sensitivity to imipenam $(88.57 \%)$ followed by piperacillin -tazobactam $(85.71 \%)$, ceftazidime and cefepime $(82.86 \%)$. It was least sensitive to ciprofloxacin $(68.57 \%)$. findings similar to our study were reported by some authors ${ }^{3,16,27}$, While Shyamala and Sheth $^{15}$ reported higher incidence of resistance.

\section{Antibiotic susceptibility pattern of Proteus spp.}

In present study Proteus spp. showed highest sensitivity to imipenem, piperacillin-tazobactam $(84.37 \%$ each $)$, followed by piperacillin, amikacin and ciprofloxacin (78.12\% each). Moderate sensitivity was found in co-trimoxazole $(46.87 \%)$ and tetracycline $(40.63 \%)$. While Vishwanath et al reported $100 \%$ sensitivity to ciprofloxacin, cotrimoxazole, amikacin and gentamycin. Shyamala and Reddy ${ }^{15}$ noticed resistance to most of the drugs

\section{Antibiotic susceptibility pattern of Klebsiella pneumoniae}

In present study, Klebsiella pneumoniae showed highest sensitivity to imipenem $(88.2 \%)$, followed by amikacin and piperacillin-tazobactam $(82.35 \%)$. It was moderately sensitive to co-trimoxazole and tetracycline. It showed resistance to ampicillin with sensitive strains being only $23.25 \%$. Kumar and Sheth ${ }^{18}$ noticed $100 \%$ sensitivity to Piperacillin, Piperacillin-Tazobactam, ciprofloxacin while Shyamala and Reddy ${ }^{15}$ noticed resistance to most of the drugs.

Overall good susceptibility was noted to most of the antibiotics as most of the patients in present study were those attending outpatient department and probably had community acquired infection. Majority of patients were from rural areas where exposure to antibiotics is minimal.

\section{CONCLUSION}

Our study concludes that continuous and periodic evaluation of microbiological pattern and antibiotic sensitivity of isolates is necessary to decrease the potential risk of complications of CSOM by early institution of appropriate treatment. Our study will help clinicians to decide the empirical antibiotic therapy in management of CSOM patients till reports of culture and sensitivity are available to them. In fact, culture facilities are not available in many of the villages from our area in such conditions also clinicians will be helped by our study findings.

\section{REFERENCES}

. Fule RP, Damle AS, Kaundinya DV. Bacteriological profile of chronic suppurative otitis media in Ambajogai. Indian medical gazette 1986;120(2):47-9.

Acuin J. Chronic suppurative otitis media. ClinicalEvidence. BMJ publishing group ltd 2007:2.507

Prakash R, Juyal D, Negi V, Pal S, Adekhandi S, Sharma M, et al. Microbiology of chronic suppurative otitis media in a teritiary care setup of Uttarakhand State, India. chronic suppurative otitis media in a teritiary care setup of U
North American Journal of Medical Sciences 2013;5(4):282-7.

4. Poorey VK, Iyer A. Study of bacterial flora in CSOM and its significance. Indian J. otolaryngol and head and neck surgery 2002;54(2):91-5.

5. Motayo BO, Ojiogwa IJ, Adeniji FO, Nwanze JC, Onoh CC, Okerentugba PO et al. Bacteria isolates and antibiotic susceptibility of ear infecton in Abeokuta, Nigeria. Report and Opinion 2012;4(4):23-6.

6. Nikakhlagh S, Khosravi AD, Fazilpour A, Sarafzadeh M, Rashidi N. Microbiologica findingsin indings Ayson PN, Lopez JEG drug sensitivity apttern at the quirino memorial medical centre (2004-2005): 

2006;21(1\&2):20-3.

8. Aduda DSO, Macharia IM, Mugwe P, Oburra H, Farragher B, Brabin B, et al. Bacteriology of chronic suppurative otitis media (CSOM) in children in Garissa district, Kenya:a point prevalence study. Int. J. Pediatr. otorhinolaryngol.(2013), http://dx.doi.org/10.1016/j.ijporl.2013.04.011

9. Collee JG, Fraser AG, Marmion BP, Simmons A, Mackie and McCartney Practical Medical Microbiology. 14th ed. New Delhi: Elsevier, a division of Reed Elsevier India Private Limited;2012.p. 113-178

10. Cheesbrough M, Laboratory practice in tropical countries. 2nd ed. Cambrige: Cambrige universitypress;2009. P. 35-45, 80-85.

11. Chander J. Textbook of medical mycology. 3rd ed. New Delhi; Mehata publishers; 2012. P. 508,515.

12. Winn WC, Koneman EW, Allen SD, Procop GW, Schreckenberger PC,Janda WM, Woods GL. Koneman"s Color Atlas and Textbook of Diagnostic Microbiology. 6th ed. United States of America, Lippincott Williams and Wilkins; 2006.p. 67-110, 635

13. Forbes BA, Sahm DF, Weissfeld AS. Baily and Scott"s Diagnostic Microbiology, 12th ed. Missouri: Mosby Elsevier Missouri; 2007. p. 187-216, 251-3.

14. CLSI. Performance standards for antimicrobial susceptibility testing; 22nd International supplement. CLSI document Wayne PA:Clinical Laboratory standards Institute;2012.

15. Shyamala R, Reddy PS. The study of bacteriological agents of chronic suppurative otitis media - Aerobic culture and evaluation. J. Microbiol. Biotech. Res. 2012;2(1):152-162.

16. Agrawal A, Kumar D, Goyal A, Goyal S, Singh N, Khandelwar G. Microbiological profile and their antimicrobial sensitivity pattern in patients of otitis media with ear profile and their antimicrobial sensitivity pattern in patients of otitis media with ear

17. Shazia PS, Janardhan RR. Aerobic bacteriology of chronic suppurative otitis media (CSOM) in a teaching hospital. J Microbiol. Res. 2012;2(4):586-9.

18. Kumar H, Seth S. Bacterial and fungal study of 100 cases of chronic suppurative otitis media. Journal of clinical and diagnostic research. $201111 ; 5(6): 1224-7$

19. Malkappa SK, Kondapaneni S, Surpam RB, Chakraverti TK. Study of aerobic bacterial isolates and their antibiotic susceptibility pattern in chronic suppurative otitis media. Indian J Otol 2012;18(3):136-9.

20. Wariso BA, Ibe SN. Bacteriology of chronic discharging ears in Port Harcourt, Nigeria. WAJM 2006;25(3):219-222

21. Loy AHC, Tan AL, Lu PKS. Microbiology of chronic suppurative otitis media in Singapore. Singapore Med J 2002;43(6):296-9

22. Singh AH, Basu R, Venkatesh A. Aerobic bacteriology of chronic suppurative otitis media in Rajahmundry, Andhra Pradesh, India. Biology and Medicine 2012;4(2):73-9.

23. Kusuma BS, Venkateswarlu K, Krishna B, Ashokreddy, Prasad RN. Study of bacteriology in chronic suppurative otitis media. Int J Med Res Health Sci 2013;2(3):510-3

24. Ashish J, Amar M, Hajare V, Sreekantha, Avinash SS, Amareshar M. To study the bacteriological and mycological profile of chronic suppurative otitis media patients and their antibiotic sensitivity pattern. Int J Pharm Bio Sci 2013;4(2):(B) 186-199.

25. Nandy A, Mallya PS, Sivarajan K. Chronic suppurative otitis media- a bacteriological study. Indian J otolaryngol 1991;43(3).

26. Vishwanath S, Mukhopadhyay C, Prakash R, Pillai S, Pujary K, Pujary P. Chronic suppurative otitis meida: optimizing initial antibiotic therapy in a tertiary care set up. Inidan J Otolaryngol Head Neck Surg 2011;64(3):285-9

27. Bansal S, Ojha T, Kumar S, Singhal A, Vyas P. Changing microbiological trends in cases of chronic suppurative otitis media patients. Int J Cur Res Rev 2013;5(15):76-81. 